\title{
The probable destructive mechanisms behind COVID-19 on male reproduction system and fertility
}

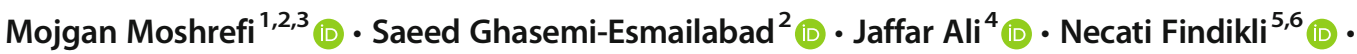 \\ Esmat Mangoli ${ }^{1,2}$ (i) $\cdot$ Mohammad Ali Khalili ${ }^{1,2}$ (1)
}

Received: 16 November 2020 / Accepted: 28 January 2021 / Published online: 11 May 2021

(C) Springer Science+Business Media, LLC, part of Springer Nature 2021

\begin{abstract}
Purpose The present study aims to summarize the current understanding of probable mechanisms and claims of adverse effects of SARS-CoV-2 on male fertility potential.

Methods Our search was including original articles, reviews, guidelines, letters to the editor, comments on guidelines, and editorials, regarding the male reproductive system. We used the words SARS-CoV-2, coronavirus, severe acute respiratory syndrome coronavirus 2, "2019 ncov," testis, sperm, male factor infertility, fertility treatment, semen, assisted reproductive technology (ART), sexual transmission, and ACE2.

Results Data showed coronavirus affects men more than women because of more expression of $2019 \mathrm{nCoV}$ receptors (ACE2 and TMPRSS2) in testicular cells. Also, "Bioinformatics Analysis" suggests that sperm production may be damaged, since "Pseudo Time Analysis" has shown disruption in spermatogenesis. "Gene Ontology" (GO) showed an increase in viral reproduction and a decrease in sperm production-related terms. Recently, SARS-COV-2 mRNA and protein were detected in the semen of patients that had recovered from SARS-CoV-2 infection. Therefore, the probable disruption of blood-testis barrier (BTB) in febrile diseases is suspected in the acute phase of the disease enabling viral entry into the testes. Not only is spermatogenesis disturbed, but also disturbs gonadotropin, androgens, and testosterone secretion during SARS-CoV-2 infection. No sexual transmission has been reported yet; however, detection of the virus in semen still makes the sexual transmission an open question.

Conclusion There is a concern that male fertility may be disturbed after the SARS-CoV-2 infection. Therefore, follow-up of the reproductive functions and male fertility may be necessary in recovered cases, especially in aged men.
\end{abstract}

Keywords COVID-19 $\cdot$ SARS-CoV-2 $\cdot$ Sperm $\cdot$ Testis $\cdot$ Male reproduction

Mohammad Ali Khalili

khalili59@hotmail.com

Mojgan Moshrefi

m.moshrefi83@yahoo.com

Saeed Ghasemi-Esmailabad

qasemisaeed@yahoo.com

Jaffar Ali

jaffarali.abdullah@gmail.com

Necati Findikli

necatif@gmail.com

Esmat Mangoli

es.mangoli@gmail.com
1 Research and Clinical Center for Infertility, Yazd Reproductive Science Institute, Shahid Sadoughi University of Medical Sciences, Yazd, Iran

2 Department of Reproductive Biology, Shahid Sadoughi University of Medical Sciences, Yazd, Iran

3 Medical Nanotechnology \& Tissue Engineering Research Center, Yazd Reproductive Science Institute, Shahid Sadoughi University of Medical Sciences, Yazd, Iran

4 Synbios Media, www.synbiosmedia.com, P.O. Box 02042 GPO Shah Alam, Selangor, Malaysia

5 Bahceci Fulya Assisted Reproduction Center, Istanbul, Turkey

6 Department of Bioengineering, Beykent University, Istanbul, Turkey 


\section{Introduction}

A few years ago, the WHO published a list of pathogens, namely Disease X (https://www.who.int/activities/ prioritizing-diseases-forresearch-and-development-inemergency-contexts) with the risk of a pandemic, with no treatment modalities as well as diagnostic tools. COVID-19 resembles most of the characteristics of Disease X [1]. Today, the world is facing an unprecedented public health problem caused by the rapidly spreading SARS-CoV-2 pandemic. At the time of writing this paper, there were more than $71,164,807$ cases of infection, over 1,597,023 mortalities, and 49,411,919 patients recovered worldwide (https://www. worldometers.info/coronavirus). Exponential increase, unknown features, and complications make this virus a challenge for healthcare professionals. During the rapid outbreak, all efforts were made to characterize the virus and develop vaccines. The probable adverse effects of the virus on the reproductive system have been overlooked because the scientific community was preoccupied with seeking means to control the disease as soon as it emerged. ACE2, the major receptor for virus entry to host cells is highly expressed in testicular cells. Also, observation of orchitis in several deceased patients and detection of the virus in the seminal fluid of infected men raised question of whether the virus impacts the male reproductive system and causes subsequent fertility problems [2].

Current literature does not have sufficient evidence to indicate or suggest that virus negatively affect the outcome of infertility treatment. However, it now appears reasonable to conclude it could have severe adverse effects on fertility. ASRM and SART have already issued warnings concerning the same [3]. No expression of ACE2 on sperm cells, no sexual, or vertical transmission has been reported. Furthermore, in the laboratory, consecutive washing and freezing protocols may reduce the viral load and the possibility of contamination. However as a stop-gap measure, fertility treatments cycles were postponed to protect healthcare staff, preventing possible adverse effects on the reproductive system and pregnancy, as well as to avoid possible virus effect on gamete integrity and function [4]. Considering the safety of laboratory staff and lack of information concerning sexual transmission, comprehensive semen analyses were not investigated. Some studies directed the analysis of semen parameters in affected patients, but larger studies are needed to elucidate the effect of the virus on semen parameters [5]. Furthermore, soon after the declaration of the SARS-CoV-2 pandemic, almost all infertility centers stopped their activities which made sample collection difficult. Therefore, semen analysis was severely limited and as a consequence, research and investigations were hampered [6]. As studies related to SARS-CoV-2 are limited, the effects of other similar viruses, especially SARS on the male gonadal system are considered.
This is because these two viruses share many similarities in their receptors, function and pathogenesis [7]. On the other hand, infertility is a long-term concern that cannot be evaluated in a short period of time after the sudden commencement of the pandemic outbreak. These gaps in our knowledge regarding the impact of SARS-CoV-2 on male fertility prompted us to gather information on the status of men that contracted SARS-CoV-2 and subsequently died or recovered from the infection. The present review aims to elucidate the impact of SARS-CoV-2 infection on male reproduction with special reference to consequent mechanisms that contribute to gonadal damage.

\section{Search methodology}

Published reports related to the SARS-CoV-2 virus have increased greatly in the past six months. We have noted one recent attempt to review the adverse effects of coronaviruses on reproduction, past and present [8]. Our search included published resources including original articles, reviews, guidelines, letters to the editor, comments on guidelines and editorials, regarding the male reproductive system. All published reports (Case reports, systematic and narrative reviews, original and clinical trial studies) were explored using the following words: SARS-CoV-2, coronavirus, SARS-CoV-2, "severe acute respiratory syndrome coronavirus 2," "2019 ncov," testis, sperm, male factor infertility, fertility treatment, semen, assisted reproductive technology (ART), sexual transmission, male reproduction, and ACE2. We surveyed all published data until December 9, 2020, from google scholar, PubMed, and Scopus. One limitation of this review is that the majority of the studies focused on the emergency nature of treatment and prevention. So, fertility treatment resumption and probable post-infection reproductive system damage still remain to be investigated.

\section{Virus biology and infertility}

In December 2019, a number of patients in the Wuhan City of China emerged with what initially appeared to be pneumonia. Subsequently, it became apparent that the disease was the manifestation of viral infection by a novel corona virus.

This novel coronavirus was named "2019 novel coronavirus," "SARS-CoV-2," or "the COVID-19 virus" by WHO and "severe acute respiratory syndrome coronavirus 2" (SARSCoV-2) by "International Committee on Taxonomy of Viruses." The genetic sequence of SARS-CoV-2 is $\geq 80 \%$ similar to that of SARS, both use the same cell entry receptor (ACE2), for infecting human cells [9]. SARS-CoV-2 is a positive-sense single-stranded RNA virus. The viral RNA genome is located inside a nucleocapsid, which is within an 
envelope [10]. The envelope comprises 3 proteins including a "Spike protein" that helps virus enter the host cells, a "membrane protein" and an "envelope protein" which are both responsible for virus assembly. The spike proteins are surface markers that create the "crown-like" appearance [11]. Two unique subunits are reported for the spike proteins: S1 and $\mathrm{S} 2$ [12]. The S1 domain functions in virus binding to the host cell membrane. However, the S2 domain is responsible for fusion of the virus to host cell membranes, so that the virus genome can enter the host cell. Many receptors on the human cell membrane were identified which are involved in S1 protein binding to host cells [13].

Transmission occurs prior to the onset of symptoms [14] mainly through respiratory droplets and fomites, because of the high expression of ACE2 on type II alveolar cells (AT2) of the lung [15]. Rothe and collaborators reported that the patients spread the virus asymptomatically during the incubation period. The question of other possible routes of infection has been raised [3]. To date, oropharyngeal swabs, blood, urine, facial and anal swabs were positive for the virus. It is not as yet known whether non-respiratory body fluids like seminal and vaginal fluids [16-18] could transmit the disease. Evidence for sexual or vertical transmission has not been reported [19]. Of interest is that more men are infected than women [19]. The main clinical manifestations of the novel disease are cough, fever, dyspnea and bilateral lung infiltration [16]. In severe cases, septic shock respiratory failure or other organ failure is known to occur $[20,21]$. The incubation period for the virus ranges from 2 to 14 days.

\section{Clinical manifestations in male reproductive system}

Previous studies have confirmed that ACE2 is a cellular receptor for SARS [22], and evidence of orchitis, testicular damage, germ cell destruction, thick basement membrane, and defective spermatogenesis were reported in patients infected with the disease [23] [24]. SARS-CoV-2 and SARS share considerable genetic identities and use the same receptor for entry into host cells. However, they differ in the reproductive propagation, SARS-CoV-2 being higher than in SARS [25]. At the onset of the pandemic, there was no evidence regarding the possible adverse effects of SARS-CoV-2 on male gonadal function [26].

SARS-CoV-2 entry to cells is mediated by the interaction between the virus spike proteins (S) and cellular ACE2 (Fig. 1). High ACE2 expression was noted in testicular cells, mostly in seminiferous ducts, where the spermatozoa are generated [27-29]. A meta-analysis by Wei et al. on scRNA-seq datasets showed that ACE2 is expressed in most prostate epithelial cell clusters, fibroblasts and pericytes, also in Leydig and Sertoli cells [30]. Another reported that ACE2 was highly expressed in

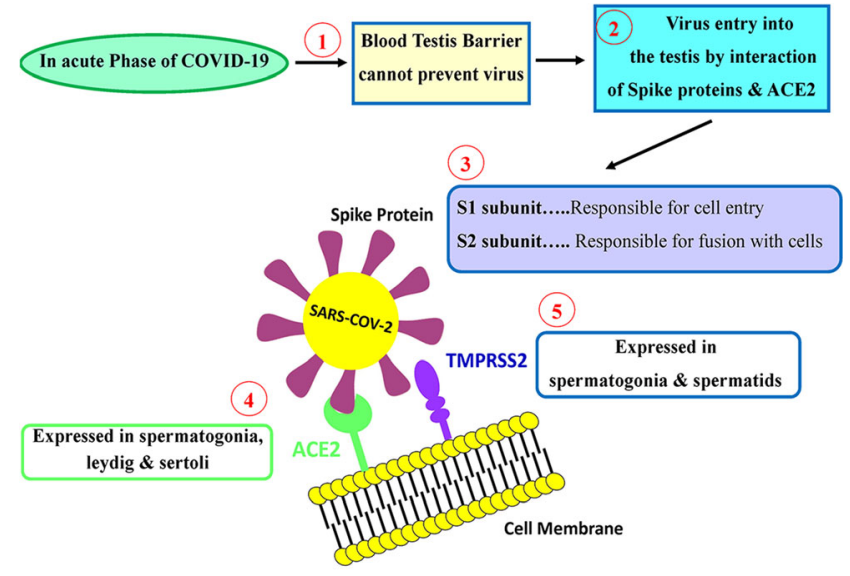

Fig. 1 The mechanisms of virus entry to cells

spermatogonia, Leydig and Sertoli cells [31]. Zhao et al. also demonstrated that ACE2 is enriched in Leydig and Sertoli cells, showing a 3-fold higher expression level than that in AT2 cells [31]. Pseudo time analysis has suggested that if spermatogonia cells were infected and damaged by SARS-CoV-2, spermatogenesis would be disrupted [28]. Other cells of spermatogenic process including spermatocytes and spermatids showed very low ACE2 expression level [28]. ACE2 plays a significant role in sperm functions [32]. When ACE2 positive cells were infected with SARS-CoV-2, male gamete production was downregulated, but viral reproduction and transmission is greatly enriched in infected ACE2-positive spermatogonia [33]. Also, in ACE2-positive Leydig and Sertoli cells, cell-to-cell junction is increased, while mitochondria and reproduction-related gene ontology are declined [28]. The Human Protein Atlas portal shows the highest expression level of ACE2 proteins and mRNA in the testicle. Likewise, other databases like FAMTOM5 and GETx have also shown the same results [34] suggesting that SARS-COV-2 may infect testis and the male reproductive system [35]. It is important to note that ACE2 expression is related to the age, with older men having the highest amount of ACE2-positive cells than younger counterparts.

\section{Biology of ACE2-positive cells by gene ontology}

Wang et al. (2020) designed a Gene Set Enrichment Analysis (GSEA) to compare ACE2-positivity in cells on the male reproductive system and they found 24 gene ontology (GO) terms, related to virus reproduction and transmission, had been positively enriched in ACE2-positive spermatogonia. Also, Wang et al. (2020) reported that while ACE2 is expressed in spermatogonia, Leydig, and Sertoli cells, TMPRSS2 mainly is expressed in spermatogonia and spermatids. GO terms related to male reproduction and sperm 
production were found to be significantly decreased in ACE2positive spermatogonia [28]. The authors also compared the characteristics of ACE2-positive Leydig and Sertoli cells with negative ones and found that $\mathrm{GO}$ terms related to cell junction and immunity were enriched in ACE2-positive cells. GO terms related to mitochondrial functions and reproduction were on the other hand found to be decreased in ACE2positive cells, indicating that ACE2-positive Leydig and Sertoli cells have a lower potential for supporting spermatogenesis after infection [28].

\section{SARS-CoV-2 and TMPRSS2 receptor}

It has been postulated that SARS-CoV-2 and SARS-CoV use ACE2 receptor for host cell entry and the transmembrane serine protease 2 (TMPRSS2) for viral spike (S) protein priming [22]. Prior to ACE2 binding, viral spike proteins undergo proteolytic priming by TMPRSS2 [22, 36, 37]. In other words, these two viruses use the endosomal cysteine proteases cathepsin $\mathrm{B}$ and $\mathrm{L}(\mathrm{CatB} / \mathrm{L})$ [38] and TMPRSS2 for priming $\mathrm{S}$ protein in the infected cells [37]. TMPRSS2 primes the $S$ protein to enhance ACE2-mediated viral entry [39]. It also helps the entry of influenza A and B into II pneumocytes [40]. TMPRSS2 expression is concentrated in spermatogonia and spermatids; however, relatively low level of TMPRSS2 was detected in other cells. It is highly expressed in the kidney, epididymis, prostate, and seminal vesicles [28]. It is mainly detected in elongated spermatids and to a lesser extent in spermatogonial stem cells [41]. According to Stanley et al., due to the lack of ACE2 and TMPRSS2 co-expression on human spermatozoa, human spermatozoa are probably not at increased risk of ACE2 and TMPRSS2 mediated direct viral entry to cells [42]. An in vitro study has shown that inhibition or knockdown of TMPRSS2 depresses the ability of SARS-CoV to host cells [43]. The human TMPRSS2 gene has a $15 \mathrm{bp}$ androgen response element (ARE). ARE is a motif, present in promoters or enhancers of genes, targeted by the androgen receptor. Androgens are the only known transcription promoter for the TMPRSS2 gene [44, 45]. The results was controversial, but, the most probable route of TMPRSS2 acquisition is via exposure to prostasomes that contain this protease capable of promoting viral fusion TMPRSS11B and TMPRSS12 as well as FURIN 6 are represented in human sperm proteomic databases. So, COVID19 binding and fusion with human spermatozoa may occur.

Dalpiaz et al. reported that ACE2 expression is affected by male sex hormones [46]. Also, ACE2 expressed on Leydig cells, which regulate LH secretion. Therefore, testosterone (T) and LH secretions may be changed, due to SARS-CoV-2 infectivity.

\section{Pathogenesis}

The main pathological mechanism of cellular damage and direct cell infection is through binding to ACE2 receptors and invasion of cells. High ACE2 expression in testis makes testicles the potential target site of the virus, so the virus is assumed to be a potential risk for infertility [27]. As for SARS, it was shown that $\mathrm{CD} 3+\mathrm{T}$ lymphocytes and CD68+ macrophages and leukocyte infiltration into the interstitial tissue of the testicles can produce interferons. Therefore, steroidogenesis and production of $\mathrm{T}$ are prevented [47, 48]. With regard to the testis, four main cell types including seminiferous duct cells, spermatogonia, Leydig, and Sertoli cells show ACE2 mRNA expression. So, spermatogenesis may be affected after SARS-CoV-2 infection and male reproductive problems may be considered the post-infection consequences of COVID-19 [27-29]. Leydig cells, which are crucial for regulating steroidogenesis and spermatogenesis, differ in ACE2 expression which is not regulated hormonally by $\mathrm{T}$ [49]. While, some researchers reported that ACE2 expression was restricted to Leydig and Sertoli cells in the testis [49] [50], others have shown that except for two types of spermatid cells, all other testicular cells express ACE2. Among them, Sertoli cells show the highest expression [51].

The second mechanism is cytokine storm-induced dysfunction. SARS-COV-2 infection brings immunosuppression and cytokine storm syndromes [52], which increases the susceptibility to infection and higher mortality rate due to decreased immunity [53]. Blood-testis barrier (BTB) protects the testicular cells, especially germ cells from cytokine storms [54]. However, the testis is not completely protected from local and systemic inflammation activators and cannot be isolated from the immune system especially when viremia occurs [47]. During the acute phase of SARS-CoV-2, BTB cannot prevent virus infiltration and infection, so the virus is shed into the reproductive tract [55]. Inflammatory cytokines, produced through cytokine storm, are locally or systematically produced by these cells. Thereby, autoimmune response promotes and destroys the seminiferous epithelium and autoimmune orchitis occurs. Subsequently, the viral infection causes deterioration of spermatogenesis, steroidogenesis, and fertility [27]. From the antibody production perspective, SARS-CoV causes severe orchitis by extensive IgG precipitation in testicular tissue, causing testicular leukocyte infiltration and germ cell damage [23]. Here, it is important to note that in SARS-CoV-2 infection, IgM antibodies only appear in serum 3-7 days after infection during the acute phase [8], but IgG appears when the virus has largely been cleared [56]. Yang et al. reported several pathological findings such as seminiferous tubule injuries, a decrease in the amount of Leydig cells, and lymphocytic inflammation in patients. They also found virus RNA in one testicular sample [57]. Leydig cells highly express ACE2. On the other hand, angiotensin II reduces LH-stimulated T 
synthesis. Also, ACE2 modulates the steroidogenic activity of Leydig cells and alter vascular and microvascular permeability. A decrease of $\mathrm{T}$ and an increase of $\mathrm{LH}$ has been reported in COVID-19. Furthermore, an increase in LH level influences endothelial cell permeability, testicular blood flow, and fluid accumulation in the testis, thereby promoting inflammation. Aging causes decrease in $T$ which further induces the dysfunction of the testicular immune system. Such a decrease may be the cause of increased incidence of severe SARS-COV-2 cases among elder males [58].

Jun (2020) proposed another hypothesis that suggests that SARS-CoV-2 affects male reproduction by regulating autophagy. Autophagy is necessary for regulating sperm morphology during spermatogenesis. In autophagy-deficient mice, there is an accumulation of cytoskeleton organization regulator which results in a disordered cytoskeleton structure. This disordered cytoskeleton leads to sperm head deformity. Autophagy promotes the degradation of intracellular lowdensity lipoprotein and cholesterol uptake which plays the role in $\mathrm{T}$ synthesis, spermatogenesis, and endocrine process [59]. So, autophagy is important even for sperm morphology or for T synthesis. ACE2 is associated with a decrease in autophagy. So, when the receptor is involved in viral entry into cells, its role in decreasing autophagy may be affected. On the other hand, it was shown that COVID-19 limits autophagy by interfering with multiple metabolic pathways. The regulation of autophagy by ACE2 confirms the effect of the SARS$\mathrm{CoV}-2$ virus on autophagy. Altogether, SARS-COV-2 infection may limit the level of autophagy [60] [61] (Fig. 2).

\section{SARS-COV-2 and orchitis}

Following the epidemic of SARS-CoV infection in 2002, orchitis was recognized as a complication of SARS [23]. The possible damage to testicles impairs spermatogenesis and extensive spermatogenic cell disruption in SARS [23]. As an abnormal manifestation, La Marca et al. reported severe bilateral testicular pain in the scrotum and inguinal lymph nodes in a 43-year-old man with lowgrade fever and delayed onset of dyspnea and other symptoms, related to SARS-COV-2. But, no redness and swelling were reported. They postulated that testicular pain could be related to epididymitis following SARS-COV-2 infection [62]. Similarly, Feng et al. reported that among 6 patients who displayed mild to moderate symptoms of SARS-COV-2 (19\%) reported scrotal discomfort and confirmed viral orchitis [6]. In another study, $2.7 \%$ of severe SARS-COV-2 patients showed orchidoptosis [33].

\section{Difference of ACE2 expression in normal and azoospermic men}

Liu et al. performed single-cell RNA sequence analysis on 853 male embryo primordial germ cells (PGCs) and 2854 normal testicular cells to detect the effects of the SARS$\mathrm{CoV}-2$ virus on the male reproductive system from embryonic to adulthood stage. They reported the expression of ACE2 in all cells of adult testes and embryonic PGCs, which was decreased with age. Also, their results showed that ACE2 expression in Sertoli cells of non-obstructive azoospermia men (NOA) is significantly decreased [51]. The ACE2 expressing spermatogonia are increased in the SARS-CoV-2 reproduction pathway [28]. On the other hand, Shen et al. indicated that in infertile men, there were a higher number of ACE2 positive cells, and over-activation of ACE2 may affect spermatogenesis and decrease fertility. Therefore, it is proposed that men with lower fertility and having higher ACE2 positive cells are more vulnerable to SARS-COV-2 [63].
Fig. 2 The mechanisms of orchitis in COVID-19

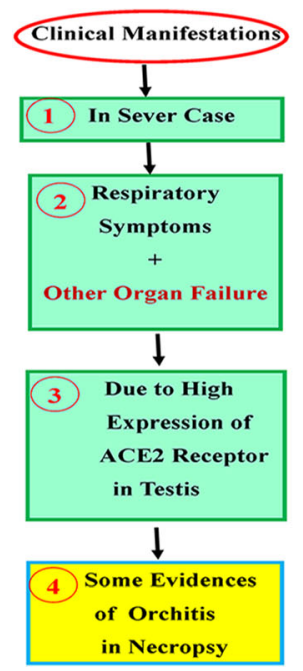

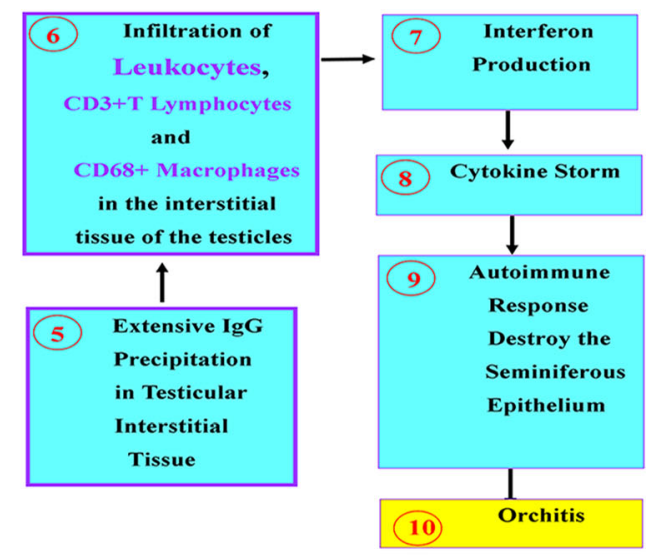




\section{SARS-CoV-1 and 2, autopsy, and testis pathology}

Orchitis is recognized as a complication for both SARS and SARS_CoV-2. Previously Xu and co-workers confirmed orchitis and inflammatory infiltration, especially in seminiferous tubules through pathological analysis, in testes of 6 patients who died of SARS [23]. Also, consistent with genomic signature and identifiable SARS viral RNA in testis, Xu et al. reported focal atrophy of testes and reproductive impairment in SARS-CoV-1[23]. Zhao et al. reported the presence of SARS-CoV in autopsies of testicular epithelial cells and Leydig cells in 2 patients who died from SARS [64]. Inflammatory infiltration in seminiferous tubules was observed and immunohistochemistry analysis showed IgG deposition in the seminiferous epithelium, interstitium, Sertoli cells, and degenerated germ cells which indicate testicular damage due to the immunological response of testes [65]. With regard to autopsies in patients that died of SARS-CoV-2, a recent study provided evidence of impaired testicular pathology through SARS-CoV-2 infection. Ma et al. reported orchitis in pathological examination including widespread destruction of germ cells, spermatogenic cell apoptosis, few or no spermatozoa in the seminiferous epithelium, leukocyte infiltration [26]. Also, Pan et al. detected scrotal discomfort in SARS-CoV-2 patients around the time of the disease [6]. Yang et al. detected several pathological changes such as a decreased number of Leydig cells and damaged Sertoli cells as well as testicular injury in 12 SARS-CoV-2 patients. Also, microscopic analysis of Sertoli cells showed swelling, vacuolation, cytoplasmic rarefaction, and detachment from basement membrane and sloughing. Interstitial edema and inflammatory infiltration, composed of CD3-positive T lymphocytes and CD68-positive histiocytes, were observed. No inflammatory cells were detected within the seminiferous tubules and no plasma cells and B lymphocytes were found in the stroma. Also, they detected the virus in the testis of several patients by RT-PCR. A range of normal to impaired spermatogenesis (from mild to severe) was detected [66]. It is necessary to note that the sensitivity of the RT-PCR test in symptomatic patients is approximately $60-95 \%$. Also, sample collection, storage and transport may adversely affect the quality of both sample and results, and increase the false-negative results [67]. So, due to limitations in the accuracy of diagnostic tests, every man and woman with infertility who refer for treatment can be potentially virus-positive, even when test results are negative [4].

\section{Virus transmission through pathological sectioning}

The European Association of Urology guidelines have no formal recommendations for fresh-frozen histopathological sections. However, an establishment of protective measures for technical and medical staff is necessary [23]. The main concern is the persistence of the virus on such surfaces including cryostats, glass, metal, and plastic for up to 9 days. Therefore, it is important to avoid contamination of fresh-frozen sections with viruses. When receiving fresh samples, pathologists and laboratory technicians should be given complete information about the patient's SARS-CoV-2 status [68]; [69]. Cryostat disinfection takes a long time, but formalin significantly decreases the infection of the virus in 1 day, also the thermal stages of sectioning render the virus non-infectious. Based on these observations, the tissues fixed with formalin are most likely not infectious [70]. However, Rocha et al. detected SARS-CoV-2 in formalin-fixed paraffin-embedded tissues of lungs and placenta with immunohistochemical (IHC) and in situ hybridization (ISH) assays [71].

\section{Sexual and vertical transmission}

Transmission through bodily fluids especially urine, semen, and vaginal fluid has not been properly elucidated. Viruses such as Zika, HIV, Ebola, and Hepatitis virus B/C can be transmitted in semen and therefore these viruses can be transmitted by sexual contact [72] [18] [73] [74] [75]. Since ACE2 has been detected in kidney and testicular cells, it is clear that SARS-CoV-2 can be found in the urogenital system especially semen, raising the question of whether shedding virus in semen indicates another possible alternative route of transmission [18]? Bioinformatics analysis revealed moderate ACE2 expression in the Fallopian tubes, prostate, and bladder, speculating that SARS-CoV-2 may infect both sperm and testis which may play a role in sexual transmission of the virus. In contrast to bioinformatics analysis, a recent report and one of the first on SARS-CoV-2 detection in semen and testis on patients recovering from SARS-CoV-23 suggested the absence of virus in semen [56]; however, their sample size was small. A much larger study is needed to conclusively determine the presence or absence of the virus in semen. Further multiple samples need to be taken even when the patient is sick or during recovery. A definitive answer will require detailed physiological and pathological examinations of the male reproductive system in recovered individuals [56]. Current disease progression statistics indicate that ART treatment should only be resumed after careful consideration of the risks involved. Freezing and frozen storage of semen samples for ART must be performed with extreme caution likewise sexual contacts without proper protection must be avoided. Since, the testis can be a reservoir for the virus it most likely may persist for a longer period of time, compared to other body fluids [3]. The presence of SARS-CoV-2 has been confirmed in autopsies of testicular epithelial cells [76]. Therefore, it is assumed that SARS-CoV-2 may also be localized in testis and seminal fluid. In addition to severe testicular tissue alterations and orchitis, the sexual transmission also appears possible. Individuals at risk or suspected to be 
infected should take all possible care to minimize the likely risk of infection through intercourse. This would mean even candidates exposed to or at risk of contracting the disease that has not yet been tested positive or those that have recovered should practice safe sex [3] to avoid disease transmission.

ACE2 is expressed on spermatozoa, but the virus entry to the cell needs co-expression of ACE2 and TMPRSS2. For this reason, it seems that spermatozoa and oocytes are not directly infected with the virus [26]. If spermatozoa and oocytes become vectors of viral transmission, they can contribute to vertical transmission [77]. Gametes of patients with other viral illnesses (HIV and hepatitis) have to be treated with special precautions to avoid cross-contamination [8]. However, these precautions have not been recommended for SARS-CoV-2, due to the lack of evidence for vertical and sexual transmission [19]. More observations and data are necessary to determine whether vertical disease transmission could occur in COVID 19 [8]. The latest public health information can be obtained from CDC website https://www.coronavirus.gov, and from NIH: https://www.nih.gov/coronavirus.

\section{Testicular immunity}

BTB, as a testicular immunity system, protects the immunogenic germ cells from the immunologic response [78]. Several viruses can enter cells of the reproductive tract by crossing the BTB and create the immune response within the testis [79]. A few studies detected the virus in semen of recovered patients and determined the mRNA and protein of ACE2 and TMPRSS2 within the human testicle [80]. Honggang reported that patients with COVID-19 shown an increase in seminal leucocytes, decreased sperm concentration, abnormal seminal leucocytes, increased concentration of CD68+ and CD3+ in the interstitial cells of testicular tissue, presence of $\operatorname{IgG}$ within seminiferous tubules, and an increase of pro-inflammatory chemokines, including IL-6, TNF-a, and MCP-1 and cytokines [81]. Also, Kaviyarasi Renu reported that COVID-19 is associated with impaired spermatogenesis, which decreases the level of T by the production of cytokines, such as TNF- $\alpha$, IL-4, IL-6, and IL-12, also TNF- $\alpha$ and interferons, leading to a decrease in sperm count. In COVID-19, T helper type 2 cells activate the IL-4 (through IgG and IgE) and mediate the apoptosis which may cause male infertility. On the other hand, IL4 decreases the level of the ACE- 2 which leads to male infertility in COVID-19 [82]. High level of IL-6S is observed in severe cases of COVID-19 and its receptors are highly expressed in testicular cells [83]. A high level of inflammatory cytokines induced by virus infections may lead to an auto-immune reaction, infiltration of leucocytes, disrupting spermatogenesis, and interfering sex-related hormonal secretion [84].

\section{Gender and age differences in SARS-CoV-2 infectivity}

Shen et al. showed that the expression of ACE2 in testis is agerelated. They confirmed that patients at 30 years of age have the highest expression level and it is higher than those at 20 years of age. In contrast, patients in the 1960s show the lowest level of expression. Although mortality is higher in older patients, the above findings also confirm that young patients are at higher risk of testicular and reproductive system damages than the older ones [29]. That is, younger men who are actively involved in reproduction may consequently experience that their ability to procreate can be severely compromised due to testis damage, leading to fertility problems after they recover from infection. Also, it should also be taken into account that the number of pediatric patients may be underestimated and children manifest silent or moderate to a mild form of the disease with different characteristics of infection compared to adults [85].

The rate of severe cases is extremely low in children under the age of 14. In several studies, the severity of the disease was linked with lifestyle habits $[16,86]$. One study reported that the median age of patients was higher in severe than mild cases. Eighty-six percent (86\%) of severely affected patients were more than 40 years old and $90 \%$ of patients with milder forms of the infection are less than 70 years old [33]. The reason may be due to the decrease of ACE2 in testicular cells with age [51]. Taken together these findings suggest older male patients should get more attention and treatment when they were still in the mild stages of the disease [30].

"Chinese Center for Disease Control and Prevention" showed that sex differences are probably a risk factor for mortality, although there are no gender differences in morbidity [87]. A meta-analysis was performed by Wenham et al. to reveal the precise correlation between sex differences and prevalence, severity, and mortality of SARS-CoV-2. It was found that men had a noticeably increased risk of severity and mortality compared to women [88]. The definitive mechanism is not clear, but the possible reason is the secretion of E2 in women [89] and the high plasma level of $\mathrm{T}$ in men, which stimulates the transcription of TMPRSS2 [90]. Another probable mechanism for the difference in prevalence and severity of SARS-CoV-2 in male and female patients is due to the difference in ACE2 expression in female and male gonads [51]. The difference in severity and mortality seen in males can also be associated with the higher smoking rate in men than women [91]. Also, another underlying difference between males and females is due to $\operatorname{IgG}$ antibody production. In mild, general, and recovering patients, the IGg concentration showed no differences between males and females. However, in severe cases, females have a relatively high concentration of serum IgG antibody. Production of $\mathrm{IgG}$ in females at the early stage of SARS-CoV-2 is stronger than in 
men [92]. Males and females have the same prevalence but men are at higher risk for death and worse outcomes, independent of age [93].

\section{Virus detection in testicular cells and semen}

Studies investigating the presence of virus in semen are limited and conflicting. The virus has been detected in the testis of deceased patients during autopsy [33]. The bioinformatics and immunohistochemistry studies showed that the virus may attack the testis. But for confirming these results, semen analysis should be done to answer these questions. Segar et al. indicated that sperm concentration and motility decrease 72-90 days after recovery [8]. In a study by Ruan et al. on 74 men who recovered from COVID-19, total sperm count, concentration and total motility were significantly decreased [94]. Pan et al. did not detect any evidence of the virus within the semen of recovered adult males, and they assumed that the virus may not be able to enter human testicular cells through an ACE2/TMPRSS2-mediated mechanism [6]. In another study, 17 patients with SARS-CoV-2 were selected to evaluate the presence of virus in their semen specimens. The results showed that all 17 patients displayed negative results for RNA of viral genes, meaning that the virus was not present in semen. Song et al. also conducted a study to examine the presence of 2019-nCoV RNA in semen and testicular samples of 12 young patients in their recovery phase. All semen samples from patients, who were negative in SARS-CoV-2 RNA tests and who were positive for 2019-nCoV RNA tests, showed no detectable SARS-CoV-2 RNA in semen, suggesting that SARS-CoV-2 does not infect the testis directly and reproductive system, at acute or recovery phase. So, they concluded that the virus is absent in the semen and the testes [56].

Paoli et al. tested the semen of one 31-year-old man, 8 days after a positive pharyngeal swap. He demonstrated unusual symptoms such as fever, myalgia, ageusia, and anosmia, but no sign of pharyngodynia, chills cough, and dyspnea. Realtime RT PCR for E and S genes showed negative results for virus RNA in semen [95]. Also, Guo et al. analyzed the semen and seminal viral RNA load of 23 patients in the acute and recovery phases of the disease. The median interval from diagnosis to collecting semen was 32 days. All patients tested negative for the virus in semen, although the virus was detected in the sputum and fecal specimen of 12 patients. Also, sperm counts, motile sperm and sperm morphology were within normal ranges [96]. Later, Nora et al. tested the semen of 18 patients. RT-PCR of semen samples showed no viral RNA even in recovered and acute SARS-CoV-2 patients [97].

In all of these studies, there exist some limitations: (1) sample sizes were in general small; (2) due to selection bias (i.e., selection of the men with milder symptoms), patients may not have developed damage to their reproductive system
[98]; (3) due to safety concerns, comprehensive semen analyses were not performed and only a single semen sample was collected a short time after recovery; (4) no evaluation of hormone profiles was performed; (5) RNA expression of ACE2 and TMPRSS2 was evaluated; however, it did not exactly reflect protein abundance (it was not possible to clearly determine their absence); (6) short subsequent follow-up was not enough to assess the long-term impact of SARS-CoV-2 on fertility and testicular endocrine function [6]. Also, multiple rounds of virus detection tests should have been performed. The results of original studies on virus detection in semen, testis, and urine are summarized in Tables 1 and 2. The reason for not detecting the virus in semen or testis could be due to the clearance of the virus from testis after its initial infection by the virus [66]. Recently, our systematic review on semen parameters and seminal fluid noted that viral mRNA was detected in semen of infected men (Khalili et al. 2020). It is proposed that the virus likely affects testicular tissue and semen parameters [101]. Anyway, the potential infectivity of virus in male reproductive tissues and semen should be strongly considered for proper management of in vitro fertilization [102].

\section{SARS-COV-2 infection and blood-testis barrier}

BTB consists of capillary endothelial cells, a basement membrane of lymphatic and myocyte-like cells, a basal membrane of seminiferous tubules, and Sertoli cells [103]. Its first role is to prevent the immune system from producing anti-sperm antibodies by blocking the antigenicity of sperm, so as to avoid autoimmune reactions. Second, it prevents harmful substances and microorganisms from entering the seminiferous tubules and interfering with spermatogenesis, and forming an impaired reproductive sperm. All together, BTB provides a safe microenvironment for spermatogenesis to better promote sperm production [104]. The question is what happens if viruses somehow broke through the BTB and entered the seminiferous tubules? Interferon $\alpha$ and $\gamma$ are produced just after contact with viruses by Leydig cells and testicular macrophages, which have the strong antiviral capability, thereby enhancing immune response for resisting viruses and other foreign cells and pathogens $[80,105,106]$. Therefore, it is reported that besides BTB, some other parts of the testicular system act as an antiviral protective barrier [107] [55]. When viremia happens, the BTB is not sufficient enough to totally prevent and limit the virus, so the virus gets access into the male reproductive tract and provokes an immune response within the testicle [55] [108]. The damage to the testis observed in autopsy samples indicated that the virus had gained entry to testicle cells. Furthermore, abnormal expression of sex hormones is the result of impaired gonadal function. So, after recovery from SARS-CoV-2 infection, young men 


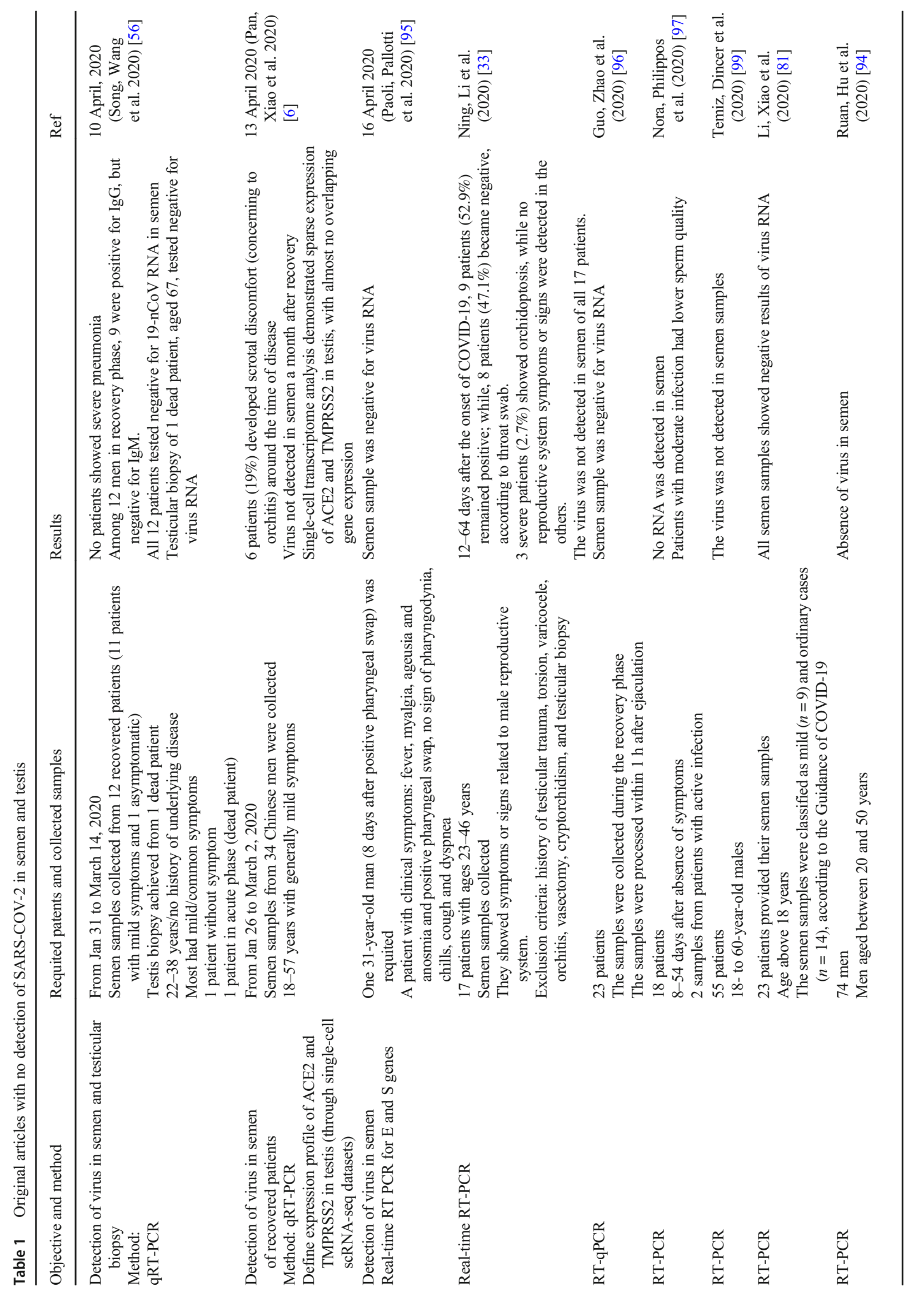


Table 2 Original articles detected SARS-COV-2 in semen

\begin{tabular}{|c|c|c|c|c|}
\hline Authors/date & Objective and Method & $\begin{array}{l}\text { Requited patent } \\
\text { and collected samples }\end{array}$ & Results & References \\
\hline Li et al. & RT-PCR & $\begin{array}{l}\text { Between Jan } 26 \text { and Feb } 16,2020 \\
\text { Semen samples collected from } 38 \\
\text { patients aged } 15 \text { years and older. } \\
\text { Except } 1 \text { patient, the rest had } \\
\text { no urogenital signs. }\end{array}$ & $\begin{array}{l}23 \text { participants }(60.5 \%) \text { achieved clinical } \\
\text { recovery. } \\
\text { The other } 15 \text { men }(39.5 \%) \text { were at the acute } \\
\text { phase. } \\
6 \text { patients }(15.8 \%) \text { tested positive for virus, } \\
\text { including } 2 \text { of } 23 \text { recovered patients }(8.7 \%) \\
\text { and } 4 \text { of } 15 \text { patients }(26.7 \%) \text { who were at } \\
\text { the acute phase. }\end{array}$ & Li, Jin et al. (2020) [100] \\
\hline
\end{tabular}

planning to have children should receive counseling for probable damage to their testes and the possibility of infertility [108]. Liu et al. showed that higher viral loads produce more severe disease symptoms which suggest that for crossing the BTB, viremia or a certain viral threshold should be achieved, which then lead to severe symptoms [98].

\section{SARS-CoV-2 virus and male hormones}

Induction of $\mathrm{LH}$ and $\mathrm{T}$ production is necessary for spermatogenesis. Any damage to Sertoli or spermatogenic cells may cause spermatogenic failure and lead to male infertility [109, 110]. Spermatogenesis and androgen secretion are two major roles of the testis. Serum T to LH ratio can act as a predictor of male gonadal function and indirectly shows the health status of the testis. The basal level of $T$ varies widely in the population; therefore, the ratio of the T/LH is considered a better parameter for evaluating male gonad function. Also, in the early stage of hypogonadism, T production may be decreased which cause the increase of $\mathrm{LH}$ and finally change the T/LH ratio $[111,112]$.

Ma et al. reported the first evidence on the effect of SARS$\mathrm{CoV}-2$ on male sex hormones among young patients that had recovered from SARS-CoV-2 infection. Although serum $\mathrm{T}$ did not statistically change, they confirmed that male gonadal function may be impaired through the SARS-CoV-2 infection because a significant increase in serum LH level was observed, which decreased the T/LH ratio and $\mathrm{FSH} / \mathrm{LH}$ ratio in patients that had recovered, compared to their healthy counterparts [26]. On the contrary, the serum FSH, estradiol (E2) and, T/E2 ratio were insignificantly different between two groups. In men, the Leydig cells are responsible for LH mediated secretion of $\mathrm{T}$ while Sertoli cells secreted inhibin B, which suppresses FSH secretion. Therefore, when there is no change in the FSH level, it is an indication that the Sertoli cells were less damaged than the Leydig's cells following SARS-CoV-2. There is a relationship between the main clinical manifestation in SARS-CoV-2 patients and the serum
$\mathrm{T}: \mathrm{LH}$ ratio. Linear regression analysis showed that $\mathrm{T}: \mathrm{LH}$ ratio in the SARS-CoV-2 patients was negatively associated with the severity, aspartate transaminase concentration (AST) and C-reactive protein (CRP) levels. But T:LH ratio is positively associated with serum AMH level. T:LH ratio is probably caused by testicular dysfunction, such as damage to Leydig cells [26]. Lower T:LH ratio is correlated with increased AST, $\mathrm{CRP}$, and AMH. The only significant correlation is related to the CRP [16]. According to a cross-sectional study by Temiz et al., serum levels of T, FSH, and $\mathrm{LH}$ decreased in acute COVID-19 due to stress. Also, sperm morphology was affected during the acute phase with high fever, as well. However, COVID-19 has no specific destructive effect on male reproductive health at short time [99].

Weijie et al. showed that a lower T:LH ratio is correlated with greater AST, CRP, and AMH levels, however only CRP is significantly correlated. Produced by the liver in the acute phase of inflammation throughout the body [26], a rapid increase in CRP levels were found to occur in severe cases, compared to non-severe cases of SARS-CoV-2 [16]. In SARS-CoV-2, elevated CRP levels are accompanied by the production of abnormal cytokines such as interferon, which influences the function of the testes and spermatogenesis [113]. In the early stages of SARS-Cov-2 infection, the CRP levels are positively correlated with lung lesions with demonstrated severity of the condition which is used as a key indicator for disease monitoring [114]. Also, Giulia and associates reported that in SARS-CoV-2 recovered patients, total testosterone (TT) level was negatively associated with the CRP level.

\section{Primary and secondary hypogonadism and SARS-CoV-2}

Low levels of $\mathrm{T}$ are referred to as hypogonadism [115]. It is associated with obesity and inflammation in men [116]. On the other hand, male hypogonadism is a risk factor for SARSCoV-2, leading to higher morbidity and mortality. 
Hypogonadism caused by obesity leads to a decrease in $\mathrm{T}$ levels. Also, the decrease of $\mathrm{T}$ leads to the progress of the cytokine storm, due to impaired immunity [117]. On the other hand, the increase of pro-inflammatory cytokines, especially IL-1 $\beta$, IL-6, and TNF- $\alpha$, which represent the inflammatory mediators in the acute phase of SARS-CoV-2, are associated with hypogonadism. As a result, hypogonadism can cause severe SARS-CoV-2 and conversely SARSCoV-2 can cause hypogonadism. It seems they have a mutual relationship [118].

\section{Male immunity and testosterone level}

$\mathrm{T}$ has a sex-specific protective effect on inflammation and vascular aging [119]. In contrast to women, T exerts a protective immune effect in men. It has been reported that in Germany, the majority of men with SARS-CoV-2 had low T and dihydrotestosterone levels, in contrast to normal levels of dihydrotestosterone in women [58]. Low T level is correlated with inflammatory cytokine expression in male SARS-CoV-2 patients. Low levels of $\mathrm{T}$ in men in SARS-CoV-2 are correlated with elevated inflammation and high levels of inflammatory cytokines, such as IFN- $\gamma$ and IL-2. Testicular immune response led to "cytokine storm" and testis damage occurred following IL-6 production [120]. T has an anti-inflammatory role. It showed a protective and immunomodulatory effect, by regulating the differentiation of T-lymphocytes [121]. Also, androgen receptor is expressed on CD4+ T cells and CD8+ T cells, whose numbers are found to be decreased in SARSCoV-2. A decrease in both $\mathrm{T}$ and these cells with androgen receptors would complicate the condition, which may become even worse with increased LH levels. It was reported that in severe case of SARS-CoV-2, T is decreased while LH is increased [117].

\section{Changes in androgen secretion in SARS-CoV-2}

Male-pattern hair loss (MPHL), which presents itself as loss of hair on the vertex of the scalp is the most common form of hair loss in men. It is referred to as androgenic alopecia (AGA) [122]. Goren et al. hypothesized that in comparison to controls, males with AGA are more likely to be hospitalized and showed severe signs of SARS-CoV-2 [123]. They conducted an observational study to understand the prevalence of AGA patients (diagnosed by dermatologists) among hospitalized SARS-CoV-2. They observed that among 41 males (mean age 58 years) admitted to hospitals with a diagnosis of SARS-CoV-2, 29 (71\%) were diagnosed with clinically significant AGA (Hamilton-Norwood scale higher than 2) and $16(39 \%)$ were classified as severe AGA (Hamilton-Norwood scale 4 to 7) [86]. In a similar age-matched Caucasian population the AGA was approximately $31-53 \%[124,125]$. The relationship between the androgen receptor and the severity of SARS-CoV-2 remains to be elucidated. If the relationship between AGA and increased severity of SARS-CoV-2 infection can be confirmed, anti-androgen therapy may potentially reduce the risk of severity and complication. Although the effect of anti-androgen therapy has not been studied yet, hydroxychloroquine, the anti-malarial drug, seems to be useful [86]. It was shown that chloroquine phosphate, an analog of hydroxychloroquine, reduced $\mathrm{T}$ in rodents [126]. Although the application of hydroxychloroquine for the treatment of SARS-CoV-2 and its potential side effects in patients are not known, it should be considered that hydroxychloroquine administration in rats caused meaningful reduction in testosterone [127]. The connection between AGA, the androgen receptor, and SARS-CoV-2 patients still remains to be elucidated. Currently, nitric oxide can be another substance to be used in the treatment for SARS-CoV-2. It was shown that nitric oxide inhibits the activity of the androgen receptor in androgen-sensitive prostate cancer [128].

\section{Relation between androgen receptor and development of SARS-CoV-2}

It was shown that ACE2 and TMPRSS2 are positively and directly regulated by the androgen receptor. In vitro and in vivo studies by Wei et al. confirmed that castration leads to the decrease of both ACE2 and TMPRSS2 receptors, while androgen supplementation therapy reversed this effect. It is probable that androgen receptors could promote the expression of ACE2 by binding to the enhancer regions of ACE2 genes [30]. The decrease in androgen level, especially the $T$ level, reduces the immunity of the testes and increases the risk of SARS-CoV-2. On the contrary, enhanced T levels can increase the expression of ACE2 and TMPPR which could increase the risk of SARS-CoV-2. Therefore, an imbalance in androgen and $\mathrm{T}$ level may trigger the pathogenesis of SARSCoV-2 in both ways [118]. Androgen receptor activity is a requirement for the transcription of the TMPRSS2. Androgen derivative therapy can decrease the expression of TMPRSS2. The decrease in TMPRSS2 can lead to a reduction in viral entry into cells [44] [129].

\section{Effect of SARS-CoV-2 on the endocrine system}

Some endocrine organs also express ACE2, specifically the thyroid, pancreas, adrenal glands, testis, ovary, and pituitary [130]. In SARS-CoV-2 infection, some drugs such as corticosteroids are used [26]. They can influence the hypothalamicpituitary-gonadal axis and its hormonal secretion will be disrupted. For example, corticosteroids impair LH release 
[131]. On the other hand, several factors like diet, drugs, and stress can influence prolactin secretion. In SARS-CoV-2 patients, serum prolactin level is also significantly elevated, which may lead to pituitary suppression and gonadotropins decrease. Other than a dysfunction of the testes, T/LH ratio changes in SARS-CoV-2 infection can also be due to changes in prolactin, pituitary suppression and gonadotropins decrease [132]. The data on neurological damage is limited, but the high incidence of neurological symptoms and immunemediated hypophysitis suggest that the hypothalamuspituitary may be affected by SARS-CoV-2 [133]. There is no report on thyroid function in SARS-CoV-2, but previously it was shown that SARS led to the destruction of thyroid destruction [134]. Hypothyroidism and thyrotoxicosis have remarkable effects on testicular function [135] therefore patients with hypothyroidism or hyperthyroidism are advised to be followed up by assessing their gonadal function. Taken together, SARS-CoV-2 may damage glands and cause several endocrine disorders including central hypocortisolism and hypothyroidism, hyperprolactinemia, hypoadrenalism, hypothyroidism, hypogonadism of parathyroid, and pancreatic damage [136].

\section{SARS-CoV-2 and sperm damage}

The SARS-CoV-2 virus has a novel non-structural polyprotein $(\mathrm{ORF} 1 \mathrm{a} / \mathrm{b})$. The origin of this short protein and its role in pathogenesis and the viral life cycle is still unknown. Veljkovic et al. analyzed the Orf3b protein by using the informational spectrum method (ISM), which helps in the functional analysis of protein sequences in the absence of prior experimental data. This technique was used for the prediction of many proteins and issues related to SARS-CoV-2 including potential receptor, natural reservoir, vaccine, tropism, and therapeutic targets of SARS-CoV-2 (https://f1000research. com/articles/9-52). After screening human proteins by using ISM and UniProt database (https://www.uniprot.org) to recognize the possible iterators of Orf3b protein, the results showed that just one protein of sperm, namely "motile sperm domain-containing protein 3" (MOSPD3), is the possible iterator of ORF1a/b [1]. MOSPD3 gene encodes a multipass membrane protein with a major sperm protein (MSP) domain. Diseases associated with MOSPD3 include Noonan syndrome and lymphogranuloma venereum (https://www. genecards.org/cgi-bin/carddisp.pl?gene=MOSPD3).

As a result of ACE2 activity, increased local availability of angiotensin II occurs, which enhances sperm phagocytosis by neutrophils and increases the local reactive oxygen species (ROS), produced during the phagocytic process. ROS induces apoptosis and cell senescence [137]. Also, angiotensin II stimulates the acrosome reaction in human sperm, therefore prolonged exposure to high levels of angiotensin II may lead to premature acrosomal exocytosis followed by sperm senescence [138] [137, 139]. Angiotensin II stimulates nitric oxide generation which is expected to stimulate sperm capacitation and acrosome reaction within a short span of time. In the longterm this leads to oxidative stress and senescence. Angiotensin II receptor is important for sperm motility. Following interaction with SARS-CoV-2 and ACE2, if the cells can progress to endocytosis, then ACE2 becomes internalized with endocytosis. However the spermatozoa are non-endocytotic cells, so following virus binding, ACE2 will be cleaved, which probably decreases sperm viability and function. So releasing ACE2 from sperm cells leads to the increase of sperm senescence and death [137]. Also, cytokines, drug-like ribavirin, decrease testosterone level, impair spermatogenesis, aggregation of the inflammatory factors, and oxidative stress may increase the sperm DNA fragmentation [140].

\section{Bioinformatics analysis}

Zhang et al. explored the probable risk of infection to the reproductive system by bioinformatics analysis of data from public databases, which involved single-cell RNA expression, RNA expression and protein expression. Their data showed high levels of ACE2 mRNA and protein expression in the lung, testis, spermatids, and uterus. They claimed that longterm complications in the reproductive system could be anticipated after SARS-CoV-2 infection [141]. Analysis of RNA sequencing in different tissues showed ACE2 expression in the respiratory, digestive urinary female reproductive system (ectocervix and ovary) and male reproductive systems (prostate and testis). The highest expression was observed in testes [141]. Interestingly, it was shown that the proportion of ACE2-positive AT2 cells in the lung was found to be approximately $1 \%$ of total AT2 cells, but SARS-CoV-2 attacks the lungs and it causes considerable damage to the lungs [141]. Co-expression of ACE2/TH1 (CD90) [142] and ACE2/MAGEA4 was identified in both somatic cells and germ cells in the testes respectively [143, 144]. MAGE-A4 is a germ cell-specific marker which is expressed differentially in testicular tumor and it is a potential target for immunotherapy [145, 146]. scRNAseq data analysis showed that the male reproductive system contains ACE2-positive cells, also spermatids shows an expression of ACE2 [141, 147]. Wang et al. conducted a single-cell transcriptome on the expression pattern of ACE2 in human testes. Their investigation showed that ACE2 was expressed in spermatogonia, Leydig, and Sertoli cells [141]. It is therefore assumed that caution must be exercised due to the potential tendency of the virus to testicular tissues and as a consequence the risk of testicular lesions [27]. 


\section{SARS-COV-2 and sperm cryopreservation}

Whether we should continue to cryopreserve sperm during pandemic or not is a very important question to be addressed from the fertility preservation and ART perspective [148]. Also, Sandro et al. published a paper, regarding andrological service during SARS-CoV-2. This concern arises due to the observation that some groups of patients experience a continuous reduction in their sperm counts which warrant emergency interventions because of its time-sensitive predisposition. From this perspective, the groups of patients that would potentially require emergency andrological and urological intervention are the following: (1) severe male factor infertility, such as azoospermic patients and patients with hypogonadotropic hypogonadism; (2) cryptozoospermic and severe oligozoospermia men, who experience male infertility; (3) azoospermia subjected to vasoepididymostomy and vasovasostomy; (4) men at reproductive age with non-oncological conditions such as inflammatory bowel diseases and autoimmune disorders affected by inflammatory and systemic auto-immune problems that require treatment with gonadotoxic drugs; (5) men who are in remission; (6) advanced paternal age (older than 50); (7) patients with semen abnormalities that are candidates for ART. In all above cases, diagnostic semen analysis and sperm cryopreservation should not be postponed, due to the short window for treatment and those experiencing more stress, while undergoing fertility treatments [149].

On the other hand, it is already known that viremic patients shed viruses into semen [150]. Some viruses like Zika remains in semen about 1-year post-recovery [151]. The influenza virus, even after 40 years of cryopreservation, can remain infectious [152] [152]. Both influenza and SARS-CoV-2 have enveloped RNA viruses, so probably SARS-CoV-2 may remain viable, too. Although so far there are no reports indicating viral cross-contamination between cryopreserved semen samples, SARS-CoV-2 may be present in semen and liquid nitrogen that could pose a serious long-term health hazards for both to the patients and healthcare workers.

Moreover, as a precautionary measure, the room with nitrogen tanks should be maintained with minimum workers and minimal operation. Planning of reopening for ART treatment service was mandatory because some fertility treatment are urgent for infertile patients due to oncologic problems and couples of advanced maternal age. Sperm freezing can be done for emergency cases under intense scrutiny such as regular evaluation of symptoms, temperature checks and if possible regular viral tests. Where available, all IVF units should have these tests performed for assessing immunity in all couples or individuals entering their centers. It is sensible that protective personal equipments (PPE) are mandatory and must be worn and safe social distancing between individuals must be practiced at all times $[148,153,154]$. In ART centers that adhere to open systems for cryopreservation, it is recommended that multiple density gradient washing should be performed to remove the virus as much as possible [155, 156]. Nevertheless, prudence is required because there is still the risk of the presence of virus in semen and liquid nitrogen during and long after the cryopreservation procedure. Paoli et al. suggested that before sperm cryopreservation, a questionnaire and medical interview should be done, especially for asymptomatic and patients with no previous contact with COVID-19. Also, molecular confirmation of the absence of SARS-CoV-2 in seminal fluid ensures the safety of sperm cryopreservation [157].

\section{Follow-up}

In essence for the patients and their fertility need, long-term follow-up of spermatogenic function is of great significance. Routine semen analysis and color Doppler ultrasound methods should be used for SARS-CoV-2 patients to detect scrotal discomfort and testicular damage. Also, sex hormones should be assessed to evaluate gonadal endocrine dysfunction, especially for patients with abnormal semen analysis. T and LH are closely related to sperm count and motility [158-160]. SARS-CoV-2 causes viral orchitis, which may cause testicular mesenchymal cell damage which leads to a decrease of $\mathrm{T}$ and an increase of gonadotropin levels. It is recommended that acrosome function, sperm DNA fragmentation and anti-sperm antibodies are performed for 2019-nCoV patients with a background of infertility or abnormal semen analysis [33]. Finally, many international scientific efforts need to understand the role of SARS-CoV-2 infection on male reproductive health and function [161].

\section{Conclusion}

The unanticipated implications of the SARS-CoV-2 infection on male reproduction may lead to overlooking the dynamics of the disease that could cause serious health conditions and practice challenges for the healthcare provider. The enormous phenotypic severity, overwhelming nature and rapid outbreak of the disease, and the paucity of information and the unpreparedness confronting the healthcare providers during this pandemic compel us to study the crucial information that helps to combat the disease and possibly keep us prepared to handle the next pandemic. The theoretical possibility of testicle damage and subsequent infertility by either direct viral invasion through binding the virus to ACE2 or secondary to immunological or inflammatory response demand more and long-term follow-up studies regarding the function of the reproductive system. Also, a large proportion of infected patients are adults of reproductive age who may potentially experience testicular damage with subsequent fertility complications. 
Specific genes of the male germ cell involved in spermatogenesis are compromised in ACE2-positive cells. An alteration of the T:LH ratio also affects testicular endocrine function. The SARS-CoV-2 virus has eluded its detection in semen probably due to the small sample size. Therefore, the possible sexual transmission of the disease warrants further investigation. The message of this review is that healthcare providers should pay close attention to the testicle function in SARS-CoV-2 patients, especially those that plan to avail of fertility treatment. Long-term follow-up of spermatogenesis functioning is recommended.

Author contribution Mojgan Moshrefi: Conception, design, acquisition of data and literatures, drafting the article

Saeed Ghasemi-Esmailabad: Conception, design, acquisition of data and literatures

Jaffar Ali: Scientific and English revision of the manuscript

Necati Findikli: Scientific and English revision of the manuscript

Esmat Mangoli: Conception, design, acquisition of data and literatures

Mohammad Ali Khalili: Conception, revising the manuscript and final approval

\section{Declarations}

Conflict of interest The authors declare no competing interests.

\section{References}

1. Veljkovic V, Paessler S. COVID-19 Orf3b protein: the putative biological function and the therapeutic target. 2020.

2. Chen F, Lou D. Rising concern on damaged testis of COVID-19 patients. Urology. 2020;142:42.

3. Cardona Maya WD, Du Plessis SS, Velilla PA. SARS-CoV-2 and the testis: similarity with other viruses and routes of infection. Reprod BioMed Online. 2020;40(6):763-4.

4. Anifandis G, Messini CI, Daponte A, Messinis IE. COVID-19 and fertility: a virtual reality. Reprod BioMed Online. 2020;41(2): 157-9.

5. Witherspoon L, Fitzpatrick R, Patel P, Flannigan R, Roberts MT, Krakowsky Y, et al. Clinical pearls to managing men's health conditions during the COVID-19 pandemic. Canadian Urological Association Journal. 2020;14(5):E161-6.

6. Pan F, Xiao X, Guo J, Song Y, Li H, Patel DP, et al. No evidence of severe acute respiratory syndrome-coronavirus 2 in semen of males recovering from coronavirus disease 2019. Fertil Steril. 2020;113(6):1135-9.

7. Wu C, Zheng S, Chen Y, Zheng M. (2020) Single-cell RNA expression profiling of ACE2, the putative receptor of Wuhan 2019-nCoV, in the nasal tissue. medRxiv.

8. Segars J, Katler Q, McQueen DB, Kotlyar A, Glenn T, Knight Z et al. Prior and novel coronaviruses, COVID-19, and human reproduction: what is known? Fertil Steril. 2020.

9. Gralinski LE, Menachery VD. Return of the coronavirus: 2019nCoV. Viruses. 2020;12(2):135.

10. Graham RL, Donaldson EF, Baric RS. A decade after SARS: strategies for controlling emerging coronaviruses. Nature Reviews Microbiology. 2013;11(12):836-48.

11. Li F. Structure, function, and evolution of coronavirus spike proteins. Annual review of virology. 2016;3:237-61.
12. Gui M, Song W, Zhou H, Xu J, Chen S, Xiang Y, et al. Cryoelectron microscopy structures of the SARS-CoV spike glycoprotein reveal a prerequisite conformational state for receptor binding. Cell research. 2017;27(1):119-29.

13. Song W, Gui M, Wang X, Xiang Y. Cryo-EM structure of the SARS coronavirus spike glycoprotein in complex with its host cell receptor ACE2. PLoS pathogens. 2018;14(8):e1007236.

14. Li Q, Guan X, Wu P, Wang X, Zhou L, Tong Y, et al. Early transmission dynamics in Wuhan, China, of novel coronavirusinfected pneumonia. N Engl J Med. 2020;382(13):1199-207.

15. Zhou P, Yang X-L, Wang X-G, Hu B, Zhang L, Zhang W, et al. A pneumonia outbreak associated with a new coronavirus of probable bat origin. Nature. 2020;579(7798):270-3 .

16. Guan W-j, Ni Z-y, Hu Y, Liang W-h, Ou C-q, He J-x, Liu L, et al. Clinical characteristics of coronavirus disease 2019 in China. N Engl J Med. 2020;382(18):1708-20.

17. Peng L, Liu J, Xu W, Luo Q, Chen D, Lei Z, et al. SARS-CoV-2 can be detected in urine, blood, anal swabs, and oropharyngeal swabs specimens. J Med Virol. 2020;92(9):1676-80.

18. Wang W, Xu Y, Gao R, Lu R, Han K, Wu G et al. Detection of SARS-CoV-2 in different types of clinical specimens. Jama. 2020

19. Chen H, Guo J, Wang C, Luo F, Yu X, Zhang W, et al. Clinical characteristics and intrauterine vertical transmission potential of COVID-19 infection in nine pregnant women: a retrospective review of medical records. The Lancet. 2020;395(10226):809-15.

20. Yang X, Yu Y, Xu J, Shu H, Xia J, Liu H, et al. Clinical course and outcomes of critically ill patients with SARS-CoV-2 pneumonia in Wuhan, China: a single-centered, retrospective, observational study. Lancet Respir Med. 2020;8(5):475-81.

21. Wang P, Lu J, Jin Y, Zhu M, Wang L, Chen S. Epidemiological characteristics of 1212 COVID-19 patients in Henan, China. medRxiv. 2020.

22. Hoffmann M, Kleine-Weber H, Schroeder S, Krüger N, Herrler T, Erichsen S, et al. SARS-CoV-2 cell entry depends on ACE2 and TMPRSS 2 and is blocked by a clinically proven protease inhibitor. Cell. 2020;181(2):271-280.e8.

23. Xu J, Qi L, Chi X, Yang J, Wei X, Gong E, et al. Orchitis: a complication of severe acute respiratory syndrome (SARS). Biology of reproduction. 2006;74(2):410-6.

24. Qi L-H, Chi X-C, Xu J, Yang J-J, Gong E-C, Gu J. Pathological changes of testis tissue in SARS patients. Basic Clin Med. 2007.

25. Liu Y, Gayle AA, Wilder-Smith A, Rocklöv J. The reproductive number of COVID-19 is higher compared to SARS coronavirus. J Travel Med. 2020;27(2).

26. Ma L, Xie W, Li D, Shi L, Mao Y, Xiong Y, Zhang Y, Zhang M. Effect of SARS-CoV-2 infection upon male gonadal function: A single center-based study. medRxiv. 2020.

27. Fan C, Li K, Ding Y, Lu WL, Wang J. ACE2 expression in kidney and testis may cause kidney and testis damage after 2019-nCoV infection. MedRxiv. 2020

28. Wang Z, Xu X, et al. Cells. 2020;9(4):920.

29. Shen Q, Xiao X, Aierken A, Yue W, Wu X, Liao M, et al. The expression in Sertoli cells and germ cells may cause male reproductive disorder after SARS-CoV-2 infection. J Cell Mol Med. 2020;24(16):9472-7.

30. Wei X, Xiao Y-T, Wang J, Chen R, Zhang W, Yang Y, Lv D, Qin C, Gu D, Zhang B. Sex differences in severity and mortality among patients with COVID-19: evidence from pooled literature analysis and insights from integrated bioinformatic analysis. arXiv preprint arXiv:200313547.

31. Zhao Y, Zhao Z, Wang Y, Zhou Y, Ma Y, Zuo W. Single-cell RNA expression profiling of ACE2, the putative receptor of Wuhan 2019-nCov. https://doi.org/10.1101/2020.01.26.919985

32. Bernstein KE. The role of tissue angiotensin-converting enzyme (ACE): studies of ACE mutant mice. American Journal of Cardiology. 1998;82(9):5S-7S. 
33. Ning J, Li W, Ruan Y, Xia Y, Wu X, Hu K et al. Effects of 2019 novel coronavirus on male reproductive system: a retrospective study. 2020.

34. Shastri A, Wheat J, Agrawal S, Chaterjee N, Pradhan K, Goldfinger $\mathrm{M}$ et al. Delayed clearance of SARS-CoV2 in male compared to female patients: high ACE2 expression in testes suggests possible existence of gender-specific viral reservoirs. medRxiv. 2020.

35. Lu R, Zhao X, Li J, Niu P, Yang B, Wu H, et al. Genomic characterisation and epidemiology of 2019 novel coronavirus: implications for virus origins and receptor binding. The Lancet. 2020;395(10224):565-74.

36. Shieh W-J, Hsiao C-H, Paddock CD, Guarner J, Goldsmith CS, Tatti $\mathrm{K}$, et al. Immunohistochemical, in situ hybridization, and ultrastructural localization of SARS-associated coronavirus in lung of a fatal case of severe acute respiratory syndrome in Taiwan. Human pathology. 2005;36(3):303-9.

37. Glowacka I, Bertram S, Müller MA, Allen P, Soilleux E, Pfefferle $\mathrm{S}$, et al. Evidence that TMPRSS2 activates the severe acute respiratory syndrome coronavirus spike protein for membrane fusion and reduces viral control by the humoral immune response. Journal of virology. 2011;85(9):4122-34.

38. Simmons G, Gosalia DN, Rennekamp AJ, Reeves JD, Diamond SL, Bates P. Inhibitors of cathepsin L prevent severe acute respiratory syndrome coronavirus entry. Proceedings of the National Academy of Sciences. 2005;102(33):11876-81.

39. Chen Y-W, Lee M-S, Lucht A, Chou F-P, Huang W, Havighurst $\mathrm{TC}$, et al. TMPRSS2, a serine protease expressed in the prostate on the apical surface of luminal epithelial cells and released into semen in prostasomes, is misregulated in prostate cancer cells. The American Journal of Pathology. 2010;176(6):2986-96.

40. Limburg H, Harbig A, Bestle D, Stein DA, Moulton HM, Jaeger J, et al. TMPRSS2 is the major activating protease of influenza A virus in primary human airway cells and influenza $\mathrm{B}$ virus in human type II pneumocytes. Journal of Virology. 2019;93(21): e00649-19.

41. Carr AC, Rosengrave PC, Bayer S, Chambers S, Mehrtens J, Shaw GM. Hypovitaminosis $\mathrm{C}$ and vitamin $\mathrm{C}$ deficiency in critically ill patients despite recommended enteral and parenteral intakes. Critical Care. 2017;21(1):300.

42. Stanley KE, Thomas E, Leaver M, Wells D. Coronavirus disease19 and fertility: viral host entry protein expression in male and female reproductive tissues. Fertil Steril. 2020;114(1):33-43.

43. Heurich A, Hofmann-Winkler H, Gierer S, Liepold T, Jahn O, Pöhlmann S. TMPRSS2 and ADAM17 cleave ACE2 differentially and only proteolysis by TMPRSS2 augments entry driven by the severe acute respiratory syndrome coronavirus spike protein. Journal of virology. 2014;88(2):1293-307.

44. Lucas JM, Heinlein C, Kim T, Hernandez SA, Malik MS, True $\mathrm{LD}$, et al. The androgen-regulated protease TMPRSS2 activates a proteolytic cascade involving components of the tumor microenvironment and promotes prostate cancer metastasis. Cancer discovery. 2014;4(11):1310-25.

45. Kishk SM, Kishk RM, Yassen ASA, Nafie MS, Nemr NA, ElMasry G, et al. Molecular insights into human transmembrane protease serine-2 (TMPS2) inhibitors against SARS-CoV2: homology modelling, molecular dynamics, and docking studies. Molecules. 2020;25(21):5007.

46. Dalpiaz P, Lamas A, Caliman I, Ribeiro R Jr, Abreu G, Moyses $\mathrm{M}$, et al. Sex hormones promote opposite effects on ACE and ACE2 activity, hypertrophy and cardiac contractility in spontaneously hypertensive rats. PloS one. 2015;10(5):e0127515.

47. Hedger MP, Meinhardt A. Cytokines and the immune-testicular axis. Journal of reproductive immunology. 2003;58(1):1-26.
48. Gu J, Korteweg C. Pathology and pathogenesis of severe acute respiratory syndrome. The American journal of pathology. 2007;170(4):1136-47.

49. Douglas GC, O’Bryan MK, Hedger MP, Lee DK, Yarski MA, Smith AI, et al. The novel angiotensin-converting enzyme (ACE) homolog, ACE2, is selectively expressed by adult Leydig cells of the testis. Endocrinology. 2004;145(10):4703-11.

50. Younis JS, Abassi Z, Skorecki K. Is there an impact of the COVID-19 pandemic on male fertility? The ACE2 connection. Rockville: American Physiological Society; 2020.

51. Liu X, Chen Y, Tang W, Zhang L, Chen W, Yan Z, et al. Singlecell transcriptome analysis of the novel coronavirus (SARS-CoV2) associated gene ACE2 expression in normal and non-obstructive azoospermia (NOA) human male testes. Sci China Life Sci. 2020;63(7):1006-15.

52. Mehta P, McAuley DF, Brown M, Sanchez E, Tattersall RS, Manson JJ. COVID-19: consider cytokine storm syndromes and immunosuppression. The Lancet. 2020;395(10229):1033-4.

53. Daneshkhah A, Eshein A, Subramanian H, Roy HK, Backman V. The role of vitamin D in suppressing cytokine storm in COVID-19 patients and associated mortality. medRxiv. 2020.

54. Nemec PS, Kapatos A, Holmes JC, Stowe DM, Hess PR Cancertestis antigens in canine histiocytic sarcoma and other malignancies. Vet Comp Oncol. 2019;17(3):317-328.

55. Li N, Wang T, Han D. Structural, cellular and molecular aspects of immune privilege in the testis. Frontiers in Immunology. 2012;3: 152.

56. Song C, Wang Y, Li W, Hu B, Chen G, Xia P et al. Absence of 2019 novel coronavirus in semen and testes of COVID-19 patients. Biol Reprod. 2020.

57. Yang M, Chen S, Huang B, Zhong J-M, Su H, Chen Y-J, et al. Pathological findings in the testes of COVID-19 patients: clinical implications. European Urology Focus. 2020;6(5):1124-9.

58. Schroeder M, Tuku B, Jarczak D, Nierhaus A, Bai T, Jacobsen H, Zickler M, Mueller Z, Stanelle-Bertram S, Meinhardt A. The majority of male patients with COVID-19 present low testosterone levels on admission to Intensive Care in Hamburg, Germany: a retrospective cohort study. medRxiv. 2020.

59. Zhu Y, Yin Q, Wei D, Yang Z, Du Y, Ma Y. Autophagy in male reproduction. Systems Biology in Reproductive Medicine. 2019;65(4):265-72.

60. Schneider M, Ackermann K, Stuart M, Wex C, Protzer U, Schätzl $\mathrm{HM}$, et al. Severe acute respiratory syndrome coronavirus replication is severely impaired by MG132 due to proteasomeindependent inhibition of M-calpain. Journal of Virology. 2012;86(18):10112-22.

61. Jun S. The hypothesis that SARS-CoV-2 affects male reproductive ability by regulating autophagy. Medical Hypotheses. 2020;110083.

62. La Marca A, Busani S, Donno V, Guaraldi G, Ligabue G, Girardis M. Testicular pain as an unusual presentation of COVID-19: a brief review of SARS-CoV-2 and the testis. Reprod BioMed Online. 2020;41(5):903-6.

63. Shen Q, Xiao X, Aierken A, Yue W, Wu X, Liao M, et al. The expression in Sertoli cells and germ cells may cause male reproductive disorder after SARS-CoV-2 infection. J Cell Mol Med. 2020;24(16):9472-7.

64. Zhao J, Zhou G, Sun Y. SARS coronavirus could cause multiorgan infection. Med J Chin People's Liberation Army. 2001(08).

65. Zhan J, Deng R, Tang J, Zhang B, Tang Y, Wang JK, et al. The spleen as a target in severe acute respiratory syndrome. The FASEB Journal. 2006;20(13):2321-8.

66. Yang M, Chen S, Huang B, Zhong J-M, Hua S, Chen Y-J, et al. Pathological findings in the testes of COVID-19 patients: clinical implications. Eur Urol Focus. 2020;6(5):1124-9. 
67. He J-L, Luo L, Luo Z-D, Lyu J-X, Ng M-Y, Shen X-P, et al. Diagnostic performance between CT and initial real-time RTPCR for clinically suspected 2019 coronavirus disease (COVID19) patients outside Wuhan, China. Respiratory Medicine. 2020;168:105980.

68. Hanley B, Lucas SB, Youd E, Swift B, Osborn M. Autopsy in suspected COVID-19 cases. Journal of Clinical Pathology. 2020;73(5):239-42.

69. Barton LM, Duval EJ, Stroberg E, Ghosh S, Mukhopadhyay S. Covid-19 autopsies, Oklahoma, USA. American Journal of Clinical Pathology. 2020;153(6):725-33.

70. Rossi ED, Fadda G, Mule A, Zannoni GF, Rindi G. Cytologic and histologic samples from patients infected by the novel coronavirus 2019 SARS-CoV-2: An Italian institutional experience focusing on biosafety procedures. Cancer Cytopathol. 2020;128(5):31720.

71. Rocha AB, Stroberg E, Barton LM, Duval EJ, Mukhopadhyay S, Yarid N, et al. Detection of SARS-CoV-2 in formalin-fixed paraffin-embedded tissue sections using commercially available reagents. Lab Invest. 2020;100(11):1485-9.

72. Puggioni G, Pintus D, Melzi E, Meloni G, Rocchigiani AM, Maestrale $\mathrm{C}$, et al. Testicular degeneration and infertility following arbovirus infection. Journal of Virology. 2018;92(19): e01131-18.

73. Gu J, Gong E, Zhang B, Zheng J, Gao Z, Zhong Y, et al. Multiple organ infection and the pathogenesis of SARS. J Exp Med. 2005;202(3):415-24.

74. Maya WDC, Du Plessis SS, Velilla PA. Semen as virus reservoir? Journal of Assisted Reproduction and Genetics. 2016;33(9):12556.

75. Cardona-Maya WD, Hernandez PAV, Henao DE. Male Ebola survivors: do not forget to use a condom! Reproductive sciences. 2019;26(10):1326.

76. Jingmin Z, Guangde Z, Yanling S. SARS coronavirus could cause multi-organ infection. Medical Journal of Chinese People's Liberation Army. 2003;8:14.

77. Schwartz DA. An analysis of 38 pregnant women with COVID19 , their newborn infants, and maternal-fetal transmission of SARS-CoV-2: maternal coronavirus infections and pregnancy outcomes. Arch Pathol Lab Med. 2020;144(7):799-805.

78. Salam AP, Horby PW. The breadth of viruses in human semen. Emerging Infectious Diseases. 2017;23(11):1922.

79. Liu W, Han R, Wu H, Han D. Viral threat to male fertility. Andrologia. 2018;50(11):e13140.

80. Zhao S, Zhu W, Xue S, Han D. Testicular defense systems: immune privilege and innate immunity. Cellular \& Molecular Immunology. 2014;11(5):428.

81. Li H, Xiao X, Zhang J, Zafar MI, Wu C, Long Y, et al. Impaired spermatogenesis in COVID-19 patients. EClinicalMedicine. 2020;28:100604.

82. Renu K, Subramaniam MD, Chakraborty R, Haritha M, Iyer M, Bharathi G, et al. The role of Interleukin-4 in COVID-19 associated male infertility-a hypothesis: running title: IL- 4 and its role in COVID-19 associated male infertility. Journal of Reproductive Immunology. 2020;142:103213.

83. Ren X, Wei X, Li G, Ren S, Chen X, Zhang T et al. Multiple expression assessments of ACE2 and TMPRSS2 SARS-CoV-2 entry molecules in the urinary tract and their associations with clinical manifestations of COVID-19. bioRxiv. 2020.

84. Haghpanah A, Masjedi F, Alborzi S, Hosseinpour A, Dehghani A, Malekmakan L, et al. Potential mechanisms of SARS-CoV-2 action on male gonadal function and fertility: Current status and future prospects. Andrologia. 2020;53:e13883.

85. Paraluppi V, Pintus MC, Fanos V, Marcialis MA. COVID-19 in newborns and in children: the state of the art. Journal of Pediatric and Neonatal Individualized Medicine (JPNIM). 2020;9(1): e090138.

86. Goren A, Vaño-Galván S, Wambier CG, McCoy J, GomezZubiaur A, Moreno-Arrones OM, et al. A preliminary observation: Male pattern hair loss among hospitalized COVID-19 patients in Spain - A potential clue to the role of androgens in COVID-19 severity. J Cosmet Dermatol. 2020;19(7):1545-7.

87. The epidemiological characteristics of an outbreak of 2019 novel coronavirus diseases (COVID-19) in China. Zhonghua Liu Xing Bing Xue Za Zhi. 2020;41(2):145-51. https://doi.org/10.3760/ cma.j.issn.0254-6450.2020.02.003.

88. Wenham C, Smith J, Morgan R. COVID-19: the gendered impacts of the outbreak. The Lancet. 2020;395(10227):846-8.

89. Liu J, Ji H, Zheng W, Wu X, Zhu JJ, Arnold AP, et al. Sex differences in renal angiotensin converting enzyme 2 (ACE2) activity are $17 \beta$-oestradiol-dependent and sex chromosome-independent. Biology of Sex Differences. 2010;1(1):6.

90. Voinsky I, Baristaite G, Gurwitz D. Effects of age and sex on recovery from COVID-19: Analysis of 5769 Israeli patients. J Infect. 2020;81(2):e102-3.

91. Cai H. Sex difference and smoking predisposition in patients with COVID-19. The Lancet Respiratory Medicine. 2020;8(4):e20.

92. Zeng F, Dai C, Cai P, Wang J, Xu L, Li J, et al. A comparison study of SARS-CoV-2 IgG antibody between male and female COVID-19 patients: A possible reason underlying different outcome between sex. J Med Virol. 2020;92(10):2050-4.

93. Jin J-M, Bai P, He W, Wu F, Liu X-F, Han D-M, et al. Gender differences in patients with COVID-19: Focus on severity and mortality. Frontiers in Public Health. 2020;8:152.

94. Ruan Y, Hu B, Liu Z, Liu K, Jiang H, Li H, et al. No detection of SARS-CoV-2 from urine, expressed prostatic secretions, and semen in 74 recovered COVID-19 male patients: A perspective and urogenital evaluation. Andrology. 2021;9(1):99-106.

95. Paoli D, Pallotti F, Colangelo S, Basilico F, Mazzuti L, Turriziani $\mathrm{O}$ et al. Study of SARS-CoV-2 in semen and urine samples of a volunteer with positive naso-pharyngeal swab. J Endocrinol Invest. 2020:1-4.

96. Guo L, Zhao S, Li W, Wang Y, Li L, Jiang S et al. Absence of SARS-CoV-2 in semen of a COVID-19 patient cohort. Andrology. 2020.

97. Nora H, Philippos E, Marcel A, Cornelius D, Dunja B-B, Ortwin A et al. Assessment of SARS-CoV-2 in human semen-a cohort study. Fertil Steril. 2020.

98. Liu Y, Yan LM, Wan L, Xiang TX, Le A, Liu JM, et al. Viral dynamics in mild and severe cases of COVID-19. Lancet Infect Dis. 2020;20(6). https://doi.org/10.1016/S1473-3099(20)30232-2.

99. Temiz MZ, Dincer MM, Hacibey I, Yazar RO, Celik C, Kucuk $\mathrm{SH}$ et al. Investigation of SARS-CoV-2 in semen samples and the effects of COVID-19 on male sexual health by using semen analysis and serum male hormone profile: a cross-sectional, pilot study. Andrologia. 2020:e13912.

100. Li D, Jin M, Bao P, Zhao W, Zhang S. Clinical characteristics and results of semen tests among men with coronavirus disease 2019 . JAMA Network Open. 2020;3(5):e208292.

101. Vishvkarma R, Rajender S. Could SARS-CoV-2 affect male fertility? Andrologia. 2020;52(9):e13712.

102. Pascolo L, Zito G, Zupin L, Luppi S, Giolo E, Martinelli M, et al. Renin angiotensin system, COVID-19 and male fertility: any risk for conceiving? Microorganisms. 2020;8(10):1492.

103. Mruk DD, Cheng CY. The mammalian blood-testis barrier: its biology and regulation. Endocrine Reviews. 2015;36(5):564-91.

104. Cheng CY, Mruk DD. The blood-testis barrier and its implications for male contraception. Pharmacological Reviews. 2012;64(1): $16-64$. 
105. Kazi SAF, Shah MG, Gandahi JA, Rathi SL. Testicular histomorphology. The Professional Medical Journal. 2016;23(10):1209-13.

106. Hedger MP. Immunophysiology and pathology of inflammation in the testis and epididymis. Journal of andrology. 2011;32(6): $625-40$.

107. Shil NK, Pokharel SM, Bose S. Inflammasome activation by paramyxoviruses. Current Clinical Microbiology Reports. 2017;4(3): $150-8$.

108. Wang S, Zhou X, Zhang T, Wang Z. The need for urogenital tract monitoring in COVID-19. Nat Rev Urol. 2020:1-2.

109. Chen S-R, Liu Y-X. Regulation of spermatogonial stem cell selfrenewal and spermatocyte meiosis by Sertoli cell signaling. Reproduction. 2015;149(4):R159-R67.

110. Zirkin BR, Papadopoulos V. Leydig cells: formation, function, and regulation. Biology of Reproduction. 2018;99(1):101-11.

111. Al-Alawi I, Goud TM, Al-Harasi S, Rajab A. Cytogenetic studies of 1232 patients with different sexual development abnormalities from the Sultanate of Oman. Reproductive Biomedicine Online. 2016;32(2):162-9.

112. Lardone M, Piottante A, Valdevenito R, Ebensperger M, Castro A. Histological and hormonal testicular function in oligo/ azoospermic infertile men. Andrologia. 2013;45(6):379-85.

113. Wassie T, Fanmei Z, Jiang X, Liu G, Girmay S, Min Z, et al. Recombinant B2L and Kisspeptin-54 DNA vaccine induces immunity against Orf virus and inhibits spermatogenesis in rats. Scientific Reports. 2019;9(1):1-11.

114. Wang L. C-reactive protein levels in the early stage of COVID-19. Médecine et Maladies Infectieuses. 2020;50(4):332-4.

115. Carnegie C. Diagnosis of hypogonadism: clinical assessments and laboratory tests. Reviews in Urology. 2004;6(Suppl 6):S3.

116. Corona G, Goulis DG, Huhtaniemi I, Zitzmann M, Toppari J, Forti G, et al. European Academy of Andrology (EAA) guidelines on investigation, treatment and monitoring of functional hypogonadism in males. Andrology. 2020;8(5):970-87.

117. Rastrelli G, Di Stasi V, Inglese F, Beccaria M, Garuti M, Di Costanzo D, et al. Low testosterone levels predict clinical adverse outcomes in SARS-CoV-2 pneumonia patients. Andrology. 2021;9(1):88-98.

118. Dutta S, Sengupta P. SARS-CoV-2 and male infertility: possible multifaceted pathology. Reproduct Sci. 2020:1-4.

119. Araujo AB, Dixon JM, Suarez EA, Murad MH, Guey LT, Wittert GA. Endogenous testosterone and mortality in men: a systematic review and meta-analysis. The Journal of Clinical Endocrinology \& Metabolism. 2011;96(10):3007-19.

120. Cheung KKT, Luk AOY, So WY, Ma RCW, Kong APS, Chow FCC, et al. Testosterone level in men with type 2 diabetes mellitus and related metabolic effects: a review of current evidence. Journal of diabetes investigation. 2015;6(2):112-23.

121. Vignozzi L, Gacci M, Cellai I, Santi R, Corona G, Morelli A, et al. Fat boosts, while androgen receptor activation counteracts, $\mathrm{BPH}-$ associated prostate inflammation. The Prostate. 2013;73(8):789800.

122. Gan DCC, Sinclair RD. Prevalence of male and female pattern hair loss in Maryborough. J Investig Dermatol Sympos Proc. 2005;10(3):184-9.

123. Goren A, Mc Coy J, Wambier CG, Vano-Galvan S, Shapiro J, Dhurat $\mathrm{R}$ et al. What does androgenetic alopecia have to do with COVID-19? An insight into a potential new therapy. Dermatol Ther. 2020.

124. Severi G, Sinclair R, Hopper J, English D, McCredie M, Boyle P, et al. Androgenetic alopecia in men aged 40-69 years: prevalence and risk factors. British Journal of Dermatology. 2003;149(6): 1207-13.
125. Hamilton JB. Patterned loss of hair in man: types and incidence. Annals of the New York Academy of Sciences. 1951;53(3):708 28.

126. Nicola W, Khayria M, Osfor M. Plasma testosterone level and the male genital system after chloroquine therapy. Bollettino chimico farmaceutico. 1997;136(1):39-43.

127. Khezri MS, Shariati M, Mokhtari M, Khezri MR. The effect of hydroxychloroquine sulfate on concentration of LH, FSH and testosterone in adult male rats. 2007.

128. Cronauer M, Ince Y, Engers R, Rinnab L, Weidemann W, Suschek C, et al. Nitric oxide-mediated inhibition of androgen receptor activity: possible implications for prostate cancer progression. Oncogene. 2007;26(13):1875-84.

129. Ory J, Lima TFN, Towe M, Frech FS, Best JC, Kava BR et al. Understanding the complex relationship between androgens and SARS-CoV2. Urology. 2020.

130. Liu F, Long X, Zou W, Fang M, Wu W, Li W et al. Highly ACE2 expression in pancreas may cause pancreas damage after SARSCoV-2 infection. medRxiv. 2020.

131. Breen KM, Karsch FJ. Does cortisol inhibit pulsatile luteinizing hormone secretion at the hypothalamic or pituitary level? Endocrinology. 2004;145(2):692-8.

132. Brown RS, Khant Aung Z, Phillipps HR, Barad Z, Lein H-J, Boehm U, et al. Acute suppression of LH secretion by prolactin in female mice is mediated by kisspeptin neurons in the arcuate nucleus. Endocrinology. 2019;160(5):1323-32.

133. Kaiser UB, Mirmira RG, Stewart PM. Our response to COVID-19 as endocrinologists and diabetologists. Oxford University Press US; 2020.

134. Wei L, Sun S. Xu C-h, Zhang J, Xu Y, Zhu H et al. Pathology of the thyroid in severe acute respiratory syndrome. Human pathology. 2007;38(1):95-102.

135. La Vignera S, Vita R, Condorelli RA, Mongioì LM, Presti S, Benvenga $S$, et al. Impact of thyroid disease on testicular function. Endocrine. 2017;58(3):397-407.

136. Somasundaram NP, Ranathunga I, Ratnasamy V, Wijewickrama PSA, Dissanayake HA, Yogendranathan N, et al. The impact of SARS-Cov-2 virus infection on the endocrine system. Journal of the Endocrine Society. 2020;4(8):bvaa082.

137. Aitken RJ. COVID-19 and human spermatozoa-Potential risks for infertility and sexual transmission? Andrology. 2021;9(1):48 52

138. Köhn FM, Müller C, Drescher D, Neukamm C, Mulla KE, Henkel $\mathrm{R}$, et al. Effect of angiotensin converting enzyme (ACE) and angiotensins on human sperm functions. Andrologia. 1998;30(4-5): 207-15.

139. Valdivia A, Cortés L, Beitia M, Totorikaguena L, Agirregoitia N, Corcostegui B, et al. Role of angiotensin-(1-7) via MAS receptor in human sperm motility and acrosome reaction. Reproduction. 2020;159(3):241-9.

140. Sengupta P, Dutta S. Does SARS-CoV-2 infection cause sperm DNA fragmentation? Possible link with oxidative stress. Eur J Contracept Reprod Health Care. 2020;10(13625187.2020): 1787376.

141. Zhang J, Wu Y, Wang R, Lu K, Tu M, Guo H et al. Bioinformatic analysis reveals that the reproductive system is potentially at risk from SARS-CoV-2. 2020.

142. Zheng Y, He Y, An J, Qin J, Wang Y, Zhang Y, et al. THY1 is a surface marker of porcine gonocytes. Reproduction, Fertility and Development. 2014;26(4):533-9.

143. Abbasi H, Tahmoorespur M, Hosseini SM, Nasiri Z, Bahadorani M, Hajian M, et al. THY1 as a reliable marker for enrichment of undifferentiated spermatogonia in the goat. Theriogenology. 2013;80(8):923-32. 
144. Reding SC, Stepnoski AL, Cloninger EW, Oatley JM. THY1 is a conserved marker of undifferentiated spermatogonia in the prepubertal bull testis. Reproduction. 2010;139(5):893-903.

145. Aubry F, Satie AP, Rioux-Leclercq N, Rajpert-De Meyts E, Spagnoli GC, Chomez P, et al. MAGE-A4, a germ cell specific marker, is expressed differentially in testicular tumors. Cancer. 2001;92(11):2778-85.

146. Wu J, Song W, Zhu H, Niu Z, Mu H, Lei A, et al. Enrichment and characterization of Thy1-positive male germline stem cells (mGSCs) from dairy goat (Capra hircus) testis using magnetic microbeads. Theriogenology. 2013;80(9):1052-60.

147. Zou X, Chen K, Zou J, Han P, Hao J, Han Z. Single-cell RNA-seq data analysis on the receptor ACE2 expression reveals the potential risk of different human organs vulnerable to $2019-\mathrm{nCoV}$ infection. Front Med. 2020;14(2):185-92.

148. Yakass MB, Woodward B. COVID-19: should we continue to cryopreserve sperm during the pandemic? Reprod BioMed Online. 2020;40(6):905.

149. Esteves SC, Lombardo F, Garrido N, Alvarez J, Zini A, Colpi GM et al. SARS-CoV-2 pandemic and repercussions for male infertility patients: a proposal for the individualized provision of andrological services. Andrology. 2020.

150. Crespillo-Andujar C, Díaz-Menéndez M, Mora-Rillo M. Evidence for previously unidentified sexual transmission of protozoan parasites. Emerging infectious diseases. 2018;24(3):602.

151. Kurscheidt FA, Mesquita CS, Damke GM, Damke E. Analine RdA, Suehiro TT et al. Persistence and clinical relevance of Zika virus in the male genital tract. Nature Reviews Urology. 2019;16(4):211-30.

152. Merrill D, Wade C, Fahnestock P, Baker R. Long-term and shortterm stability of viruses depend on storage temperature and preservation methods. URL: http://www beiresources org/Portals/2/ PDFS/Long-Term\% 20and\% 20Short-Term\% 20Stability\% 20of\% 20Viruses pdf (Accessed 24 February 2012). 2012.
153. Sheng G, Chen P, Wei Y, Yue H, Chu J, Zhao J et al. Viral infection increases the risk of idiopathic pulmonary fibrosis: a meta-analysis. Chest. 2019.

154. Meseguer M, Niederberger C, Pellicer A. Deep inside the pandemic, from inactivity to action: let's be ready. Fertil Steril. 2020.

155. Loskutoff NM, Huyser C, Singh R, Walker DL, Thornhill AR, Morris L, et al. Use of a novel washing method combining multiple density gradients and trypsin for removing human immunodeficiency virus-1 and hepatitis C virus from semen. Fertil Steril. 2005;84(4):1001-10.

156. Hanson BM, Dorais JA. Reproductive considerations in the setting of chronic viral illness. American Journal of Obstetrics and Gynecology. 2017;217(1):4-10.

157. Paoli D, Pallotti F, Nigro G, Aureli A, Perlorca A, Mazzuti L et al. Sperm cryopreservation during the SARS-CoV-2 pandemic. J Endocrinol Invest. 2020:1-6.

158. Liu Z, Shi X, Wang L, Yang Y, Fu Q, Tao M. Associations between male reproductive characteristics and the outcome of assisted reproductive technology (ART). Biosci Rep. 2017;37(3):BSR20170095.

159. Smith LB, Walker WH, editors. The regulation of spermatogenesis by androgens. Seminars in cell \& developmental biology; 2014: Elsevier.

160. Ring JD, Lwin AA, Köhler TS. Current medical management of endocrine-related male infertility. Asian Journal of Andrology. 2016;18(3):357.

161. Hallak J, Teixeira TA, Bernardes FS, Carneiro F, Duarte SA, Pariz JR et al. SARS-CoV-2 and its relationship with the genitourinary tract: implications for male reproductive health in the context of COVID-19 pandemic. Andrology. 2020.

Publisher's note Springer Nature remains neutral with regard to jurisdictional claims in published maps and institutional affiliations. 